\title{
Peripartum cardiomyopathy
}

INSERM

\section{Source}

INSERM. (1999). Orphanet: an online rare disease and orphan drug data base. Peripartum cardiomyopathy. ORPHA:563

Peripartum cardiomyopathy (PPCM) is an idiopathic, potentially fatal form of dilated cardiomyopathy that develops during the final month of pregnancy or within five months after delivery. 